\title{
MEASURING, EVALUATING AND ASSESSING THE TRANSMISSION OF VIBRATION THROUGH THE SEATS OF RAILWAY VEHICLES
}

\author{
Weidong Gong and Michael J. Griffin \\ Human Factors Research Unit \\ Institute of Sound and Vibration Research \\ University of Southampton \\ Southampton SO17 1BJ \\ United Kingdom \\ W.Gong@soton.ac.uk, M.J.Griffin@soton.ac.uk
}

Corresponding author:

Michael J. Griffin,

Human Factors Research Unit,

Institute of Sound and Vibration Research,

University of Southampton,

Highfield,

Southampton, SO17 1BJ,

United Kingdom.

Telephone: +44 (0)23 80592277

Email: M.J.Griffin@soton.ac.uk 


\begin{abstract}
The transmission of vibration through a passenger train seat to the seat pan and to the backrest has been measured in the fore-and-aft, lateral, and vertical directions with 12 subjects using 0.5 to $40 \mathrm{~Hz}$ random vibration (with both single-axis and tri-axial excitation) and using simulated tri-axial train vibration. There were small differences in transmissibilities obtained using single-axis and tri-axial random vibration but greater differences in transmissibilities between tri-axial random vibration and simulated train vibration. Seat effective amplitude transmissibilities (SEAT values) were similar for single-axis and tri-axial random vibration but differed between tri-axial random vibration and simulated train vibration. The SEAT values measured using both tri-axial random vibration and simulated train vibration were well predicted from the seat transmissibilities measured using single-axis random vibration. It is concluded that either single-axis or tri-axial vibration excitation can be used when quantifying the transmissibility of a seat and identifying seat resonances. The SEAT value depends on the vibration spectrum in the vehicle and so the SEAT value for a train seat cannot be obtained using vibration unlike that in a train. A useful SEAT value for a train seat can either be measured (by simulating tri-axial train vibration in a laboratory) or calculated (from measurements of vibration in a train and measurements of seat transmissibility obtained using random vibration in a laboratory). The findings of this study may assist the optimisation of seat testing standards including the laboratory method for evaluating the transmission of vibration through the seats of railway vehicles defined in a current international standard.
\end{abstract}

\title{
Keywords
}

Seat transmissibility, SEAT values, train seats, vibration isolation, vibration transmission, frequencyweighted acceleration, ISO10326-2 
Published as: Gong, W. and Griffin, M.J. (2018) Measuring, evaluating and assessing the transmission of vibration through the seats of railway vehicles. Proceedings of the Institution of Mechanical Engineers, Part F: Journal of Rail and Rapid Transit. 232, 2, p. 384-395.

\section{Introduction}

The vibration felt by seated passengers in railway vehicles is partly dependent on the vibration isolation performance of the seat. Poorly designed seats can lead to an unpleasant ride experience.

The discomfort caused by vibration depends on the magnitude of the vibration, the frequency of the vibration, the direction of the vibration, the duration of the vibration, and the location of body contact with vibration. ${ }^{1}$ The transmission of vibration through a seat differs between the three directions of translational vibration (fore-and-aft, lateral, and vertical). The transmission of vibration to the seat pan differs from the transmission of vibration to the backrest. In all directions and to both locations on the seat, there is usually a resonance causing amplification of vibration - often around $5 \mathrm{~Hz}$ in the vertical direction - and there may be attenuation of vibration at higher frequencies. ${ }^{2,3,4}$

The extent to which a seat increases or decreases the vibration discomfort caused by any direction of vibration depends on three factors: (i) the spectrum of the vibration in that direction on the floor beneath the seat, (ii) how the seat changes the spectrum of vibration reaching the body, and (iii) the extent to which the vibration spectrum reaching the body causes discomfort. These three functions of frequency are contained within a simple numerical indication of the isolation efficiency of a seat: the 'seat effective amplitude transmissibility', SEAT. ${ }^{3,5,6}$ A SEAT value predicts the vibration discomfort on a non-rigid seat relative to the vibration discomfort on a rigid seat in the same vibration environment. When considering only vertical vibration at the seat pan:

$$
\text { SEAT value }=\frac{\text { component ride value on seat pan }}{\text { component ride value on rigid seat pan }}
$$

where the 'component ride value' is the r.m.s. value of the vibration after it has been frequency-weighted to account for the frequency-dependence of vibration discomfort. ${ }^{1}$ Frequency weightings are defined in relevant standards (e.g. British Standard 6841:1987 and International Standard 2631:1997). 7,8

A SEAT value greater than 1.0 (or 100\%) indicates that, averaged over the entire frequency range (usually 0.5 to $80 \mathrm{~Hz}$ ), the vibration on the seat will cause more discomfort than the vibration on a rigid seat (or the floor beneath the seat); SEAT values less than 1.0 indicate that the seat has provided some useful attenuation. The SEAT value is influenced by the vibration input and not merely by the dynamics of the seat: different SEAT values are obtained with the same seat in different vehicles. The SEAT value indicates the suitability of a seat for attenuating a particular type of vibration.

Seats should be designed to have the lowest SEAT value compatible with other constraints - the lowest possible SEAT value may make the seat too soft or too hard to provide good static seat comfort. ${ }^{9}$ In railway carriages the SEAT value for vertical vibration is likely to be greater than 1.0 because foam cushions cannot attenuate the low frequencies that are normally dominant in the vertical vibration of such vehicles. Selecting a seat so as to minimise the SEAT value in these circumstances may not result in less vertical vibration on the seat than on the floor, but it will minimise exposure to vibration.

There is usually multi-axis vibration in a vehicle and discomfort can be experienced from vibration at the seat pan, the backrest, and the feet. A SEAT value could be calculated for the transmission of each of the three translational axes of vibration (fore-and-aft, lateral, and vertical) to the seat pan and the backrest 
Published as: Gong, W. and Griffin, M.J. (2018) Measuring, evaluating and assessing the transmission of vibration through the seats of railway vehicles. Proceedings of the Institution of Mechanical Engineers, Part F: Journal of Rail and Rapid Transit. 232, 2, p. 384-395.

(i.e., six SEAT values). However, an overall SEAT value may be more useful when assessing the overall efficiency of a seat in attenuating multi-axis vibration or multi-input vibration: ${ }^{6}$

$$
\text { SEAT }(\%)=\frac{\text { overall ride value with the seat }}{\text { overal ride value with a rigid seat }}
$$

where the 'overall ride value' is calculated from the root-sums-of-squares of all the 'component ride values' (i.e., the frequency-weighted vibration in each of the three axes of vibration on the seat pan, the backrest, and the footrest). ${ }^{1}$ This also allows for vibration in any axis beneath a seat causing vibration in any axis on the seat pan and the seat backrest (e.g., vertical floor vibration causing fore-and-aft vibration at the back).

Assuming there is no significant rotational oscillation, the vibration on a rigid seat (at the seat pan and the backrest) is the same as the vibration in the same axis on the floor. It is therefore only necessary to know the vibration on the floor beneath a non-rigid seat to know the vibration that would be measured on a rigid seat and use it to calculate the SEAT value of the non-rigid seat. In some environments pitch and roll oscillation of the floor can result in fore-and-aft and lateral oscillation, respectively, at the seat pan and the backrest. In these situations, the fore-and-aft and lateral vibration on a rigid seat is not solely due to the fore-and-aft and lateral vibration, respectively, on the floor. However, if the pitch and roll motion are known, the fore-and-aft and lateral oscillations they produce at the seat pan and the backrest can be calculated from the roll and pitch on the floor and the height of the seat pan and backrest above the floor. The overall principal remains the same: a SEAT value predicts the vibration discomfort on a non-rigid seat relative to with the vibration discomfort on a rigid seat in the same vibration environment.

The transmission of vibration through a seat depends on the dynamic response of the seat (e.g., its dynamic stiffness) and the dynamic response of the human body supported on the seat (e.g. the apparent mass of the human body). ${ }^{3}$ If the dynamic responses of both the seat and the body are the same at all magnitudes of vibration, the transmissibility of the seat (i.e. the ratio of the vibration on the seat to the vibration beneath the seat at each frequency of excitation) is independent of the magnitude of vibration. In practice the human body gets 'softer' as the magnitude of vibration increases, resulting in lower resonance frequencies at greater magnitudes..$^{10,11} \mathrm{~A}$ difference in the dynamic response of the body with different inputs is called 'nonlinearity' in the response of the human body which causes nonlinearity in the transmissibility of seats. ${ }^{3}$ Some seats also have nonlinear dynamic responses that contribute to nonlinearity in seat transmissibility.

International Standard 10326-2:2001 defines a laboratory procedure for evaluating the dynamic performance of railway passenger seats. ${ }^{12}$ It specifies how to measure seat transmissibility and the effectiveness of a seat in reducing vibration discomfort. The method utilises excitation with pseudorandom vibration $(0.5$ to $50 \mathrm{~Hz})$ reproduced separately in each of the three translational axes (fore-andaft, lateral, and vertical). The transmission of vibration within each axis is measured from the vibrating platform supporting the seat to the seat pan and to the backrest while the seat is occupied in turn by two persons having masses of $55 \mathrm{~kg}(0$ to $-5 \%)$ and $90 \mathrm{~kg}(0$ to $+5 \%)$. Sinusoidal excitations are also applied to test nonlinearity at resonance using two magnitudes of acceleration ( 0.5 and $1.0 \mathrm{~ms}^{-2}$ r.m.s.). 
Published as: Gong, W. and Griffin, M.J. (2018) Measuring, evaluating and assessing the transmission of vibration through the seats of railway vehicles. Proceedings of the Institution of Mechanical Engineers, Part F: Journal of Rail and Rapid Transit. 232, 2, p. 384-395.

The standard requires the reporting of SEAT values, but refers to them as 'weighted transmissibilities', $T_{\mathrm{Rw}}$.

Single-axis vibration excitation, usually vertical vibration, has been widely used in laboratory studies of seating dynamics. ${ }^{2,3,4}$ In a few studies, seat transmissibility has been measured with tri-axial random vibration excitation (simultaneous fore-and-aft, lateral, and vertical vibration) and the transmissibility has been found to be similar to that obtained using single-axis vibration excitation. ${ }^{13,14}$ However, transmissibilities obtained using a tri-axial simulation of recorded train vibration differed from the transmissibilities obtained with tri-axial random vibration based on the vibration spectrum defined in ISO 10326-2:2001. ${ }^{15}$

The method defined in ISO 10326-2:2001 has several potential limitations: (i) The spectrum of the random vibration excitation differs greatly from the spectra normally present in a train. This would not affect the seat transmissibility if the dynamics of the seat-body system were linear, but the apparent mass of the human body is very nonlinear ${ }^{10,16}$ and some seats have a nonlinear dynamic responses. ${ }^{2}$ (ii) The excitation occurs separately in each axis, rather than simultaneously in all axes as in a train. It is expected that there will be cross-axis effects such that vibration in one axis will contribute to vibration in other directions on the seat and the seat back. Single-axis excitation may also be less appropriate than multiple-axis train vibration because the seat-body system is nonlinear. (iii) The test is limited to two subjects (with defined weights), whereas the dynamic responses of human bodies vary greatly as a function of the frequency of vibration, not merely the body weight, and this influences the transmission of vibration through seats. ${ }^{2}$ (iv) The SEAT values calculated according to the standard will not provide good indications of the vibration isolation efficiency of seats in railway carriages because the SEAT values are calculated for a spectrum very different from the vibration spectrum in a railway vehicle.

This study was stimulated by the desire to obtain information on the importance of the above assumptions in ISO 10326-2:2001.12 The overall objective was to improve understanding of the transmission of vibration through railway passenger seats. Specifically, the research investigated experimentally: (i) the transmission of vibration in each direction of excitation using both single-axis excitation and tri-axial excitation, (ii) the nonlinearity in seat transmissibility, by measuring the dynamic response with random vibration and simulated train vibration. It was hoped that the findings could be used to specify an improved means of estimating the dynamic performance of seats in a form suitable for standardisation.

It was hypothesised that: (i) seat transmissibilities expressed as a function of frequency would be similar with the single-axis random vibration excitation specified in ISO 10326-2:2001 and with tri-axial random excitation, but not identical due to nonlinearity in the subject-seat system. (ii) A SEAT value obtained with random vibration as specified in ISO 10326-2:2001 would differ from that obtained with simulated train vibration, because the influence of seat transmissibility on a SEAT value depends on the spectrum of the vibration excitation. 
Published as: Gong, W. and Griffin, M.J. (2018) Measuring, evaluating and assessing the transmission of vibration through the seats of railway vehicles. Proceedings of the Institution of Mechanical Engineers, Part F: Journal of Rail and Rapid Transit. 232, 2, p. 384-395.

\section{Method}

\section{Apparatus}

A train double seat unit was secured to the 6-axis motion simulator in the Human Factors Research Unit of the Institute of Sound and Vibration Research at the University of Southampton. The simulator is capable of displacements of $\pm 1.0 \mathrm{~m}$ vertically and $\pm 0.5 \mathrm{~m}$ in both horizontal directions (i.e. fore-andaft and lateral). Rotational motion was not used in this study. The six-axis simulator was controlled by a Servotest Pulsar Controller.

Motion of the vibrator platform was measured using three single-axis Silicon Designs 2260-005 accelerometers attached to the platform directly below the seat. The accelerometers had an operating range of $\pm 5 \mathrm{~g}$ and a sensitivity of approximately $800 \mathrm{mV} / \mathrm{g}$. Tri-axial vibration on the surface of the seat cushion and on the backrest of the seat was measured using two tri-axial HVLab SIT-pads conforming to the specifications in ISO 10326-1 (1992) (Figure 1). ${ }^{17}$

\section{FIGURE 1 ABOUT HERE}

The SIT-pad on the seat surface was positioned beneath the ischial tuberosities of subjects. The SITpad at the backrest was centrally located $320 \mathrm{~mm}$ above the top of the relaxed seat cushion. When mounted together during calibration, the transmissibilities between the three accelerometers on the vibrator platform and the six accelerometers in the two SIT-pads were measured as $1.0 \pm 0.03$ over the 0.5 to $40 \mathrm{~Hz}$ frequency range.

A 16-channel HVLab data acquisition and analysis system was used to acquire the signals from the accelerometers: Fylde FE-366-TA amplifiers with 3-pole Butterworth low-pass filters set at $100 \mathrm{~Hz}$ and a National Instrument USB 6211 data acquisition device. Vibration acceleration was acquired at 512 samples per second.

The transmissibility of the same model of seat was measured in a train, but whereas the laboratory seat was a new seat which had not been used by passengers, the seat in the train was not new. In the train, tri-axial vibration was measured on the floor, on the seat pan, and at the backrest with a single subject sitting in the seat. The recorded vibration acceleration time-histories were provided by SNCF.

\section{Subjects}

Twelve male subjects (21 to 57 years of age, 56 to $110 \mathrm{~kg}$ total mass, 1.64 to $1.97 \mathrm{~m}$ stature as shown in Table 1) participated in the experiment that was approved by the Ethics Committee of the Faculty of Engineering and the Environment at the University of Southampton.

\section{TABLE 1 ABOUT HERE}

Subjects sat in a normal relaxed upright posture. They wore a loose-fitting safety belt and rested their hands on their laps. They were able to stop the motion of the simulator using an emergency stop button.

\section{Motion stimuli}

The seat was tested using three types of stimuli: (i) single axis random vibration applied successively in each of the three translational axes (fore-and-aft, lateral, and vertical), (ii) tri-axial random vibration, 
Published as: Gong, W. and Griffin, M.J. (2018) Measuring, evaluating and assessing the transmission of vibration through the seats of railway vehicles. Proceedings of the Institution of Mechanical Engineers, Part F: Journal of Rail and Rapid Transit. 232, 2, p. 384-395.

and (iii) a tri-axial recording of the vibration in a train. The unweighted accelerations and the weighted accelerations (weighted according to ISO 2631-1: 1997 Section 8.2.2.1) are summarised in Table 2.

\section{TABLE 2 ABOUT HERE}

International Standard 10326-2:2001 requires excitation by pseudo-random vibration composed of the sum of many sinusoidal components. In this study, so as to generate independent random vibration excitation in each of the three axes of excitation, a random number generator was used to produce signals of 90-seconds duration. After high-pass and low-pass filtering and equalisation to the response of the simulator in each axis, the power spectral density of the random excitation over the range 0.5 to $40 \mathrm{~Hz}$ was similar to that required by ISO 10326-2:2001. Three incoherent random excitations were generated in the fore-and-aft, lateral, and vertical directions. The power spectral densities of the random vibration stimuli and the recorded train vibration are compared in Figure 2.

\section{FIGURE 2 ABOUT HERE}

\section{Data analysis}

Analysis of the data was carried out using HVLab signal processing software and MATLAB (v7.11.0.584).

The frequency-weighted r.m.s. acceleration, $a_{w}$, was calculated over the 90-s duration of the motion. The SEAT value was calculated directly from ratio of the frequency-weighted r.m.s. acceleration at the seat surface and the platform. This is equivalent to the weighted transmissibility, $T_{\mathrm{Rw}}$, defined in ISO10326-2 (2001).The frequency weightings used for each calculation are identified in Table 3.

\section{TABLE 3 ABOUT HERE}

Within each axis, the transmissibility of the seat, $H(f)$, was calculated between the acceleration on the platform beneath the seat and the acceleration measured in a SIT-pad at the seat surface, using the cross-spectral density (CSD) method:

$$
H(f)=\frac{G_{i o}(f)}{G_{i i}(f)}
$$

with the coherency calculated from:

$$
\gamma_{\mathrm{io}}^{2}(f)=\frac{\left|G_{\mathrm{io}}(f)\right|^{2}}{G_{\mathrm{ii}}(f) G_{\mathrm{oo}}(f)}
$$

where $G_{\mathrm{io}}(f)$ is the cross-spectral density between acceleration at the floor (input) and the acceleration at the seat surface (output), $G_{\text {ii }}(f)$ is the power spectral density of acceleration at the floor, and $G_{\text {oo }}(f)$ is the power spectral density of the acceleration at the seat surface. Spectral functions were calculated with $0.25-\mathrm{Hz}$ resolution and 88 degrees-of-freedom.

A more complete analysis would calculate the 'conditioned' response in each axis at each output. ${ }^{18}$ This is a far more complex method that would be expected to be more appropriate for the railway excitation signals, but it is not required for the main purposes of this study and is not included so as to assist comprehension of the findings. 
For each of the three types of excitation, SEAT values were both measured and predicted.

The measured SEAT values within each axis and to both the seat pan and the backrest were calculated from:

$$
S E A T_{\text {measured }}=\left[\frac{\int_{0.5}^{50} W^{2}(f) \cdot G_{\mathrm{oo}}(f) \mathrm{d} f}{\int_{0.5}^{50} W^{2}(f) \cdot G_{\mathrm{ii}}(f) \mathrm{d} f}\right]^{1 / 2}
$$

where $G_{o o}(f)$ is the power spectral density of acceleration at the seat, $G_{i i}(f)$ is the power spectral density of acceleration at the floor, and $W(f)$ is the frequency weighting appropriate for the axis of vibration on the seat. This measured SEAT value is equivalent to the weighted transmissibility, $T_{\mathrm{Rw}}$ (i.e. $a_{w} / a_{w P}$ ), defined in ISO10326-2 (2001), where aws is the frequency-weighted r.m.s. acceleration at the seat surface and $a_{w P}$ is the frequency-weighted r.m.s. acceleration at the platform.

The predicted SEAT values were calculated from the transmissibility of the seat measured with single axis random vibration excitation:

$$
\text { SEAT } T_{\text {predicted }}=\frac{\left[\int_{0.5}^{50} G_{\mathrm{ii}}(f)|H(f)|^{2} W^{2}(f) d f\right]^{1 / 2}}{\left[\int_{0.5}^{50} G_{\mathrm{ii}}(f) W^{2}(f) d f\right]^{1 / 2}}
$$

where $G_{i i}(f)$ is the power spectral density of acceleration at the floor, $H(f)$ is the transmissibility of the seat, and $W(f)$ is the appropriate frequency weighting for vibration discomfort. This estimation procedure assumes that the seat behaves linearly and that the transmissibility of the seat can be defined at all frequencies.

\section{Results}

\section{Seat transmissibility}

The transmissibilities of the seat obtained for each of the 12 subjects with single-axis random vibration are shown in Figure 3. The median transmissibilities of the seat obtained for the 12 subjects with singleaxis random vibration, tri-axial random vibration, and tri-axial simulated train vibration are compared in Figure 4.

\section{FIGURES 3 and 4 ABOUT HERE}

The median transmissibilities to the surface of the seat cushion exhibit a primary peak around $25 \mathrm{~Hz}$ with fore-and-aft and lateral vibration excitation, and between $3.8 \mathrm{~Hz}$ and $5.0 \mathrm{~Hz}$ with vertical vibration excitation. The transmissibilities to the backrest of the seat show peaks around $4 \mathrm{~Hz}$ with fore-and-aft vibration and around $24 \mathrm{~Hz}$ with lateral and vertical vibration.

The moduli of the median transmissibilities measured with single-axis and tri-axial random excitations are similar (Figure 4). The moduli of the transmissibilities measured with random vibration and simulated train vibration are broadly similar, except for notable differences in the z-axis transmissibility to the seat 
Published as: Gong, W. and Griffin, M.J. (2018) Measuring, evaluating and assessing the transmission of vibration through the seats of railway vehicles. Proceedings of the Institution of Mechanical Engineers, Part F: Journal of Rail and Rapid Transit. 232, 2, p. 384-395.

pan around the $5-\mathrm{Hz}$ resonance, in the $x$-axis transmissibility to the backrest over much of the frequency range, and in the $\mathrm{z}$-axis transmissibility to the backrest around the $25-\mathrm{Hz}$ resonance (Figure 4).

The coherencies obtained with single-axis random excitation are close to unity, except for the transmission of fore-and-aft vibration to the backrest at frequencies greater than $30 \mathrm{~Hz}$. The coherences obtained with the simulated tri-axial train vibration are lower than those obtained with tri-axial random vibration and much lower than those obtained with single-axis random vibration. The most noticeable differences in coherences are in the fore-and-aft direction at the seat backrest, with the greatest differences at the higher frequencies (i.e., greater than $10 \mathrm{~Hz}$ ).

The primary resonance frequency in the vertical transmissibility to the seat pan was significantly lower with tri-axial random vibration than with single-axis random vibration, although the difference was not large ( $p=0.003$, Wilcoxon; Table 4$)$. Similarly, the primary resonance frequencies in the lateral transmissibilities to the seat pan and backrest were lower with tri-axial random vibration than with simulated train vibration ( $p \leq 0.004$, Wilcoxon). The primary resonance frequency in the fore-and-aft transmissibility to the seat backrest was lower with tri-axial random vibration than with simulated train vibration ( $p=0.002$, Wilcoxon).

\section{TABLE 4 ABOUT HERE}

Correlations between subject weight and resonance frequency obtained using single-axis random vibration were not statistically significant.

\section{SEAT values}

The measured SEAT values for each of the 12 subjects with the simulated train vibration, the tri-axial random excitation, and single-axis random excitation are compared in Table 5 for the seat pan and in Table 6 for the backrest. These tables also show the SEAT values predicted for the simulated train vibration and the tri-axial random excitation from the seat transfer functions measured with single-axis excitation.

\section{TABLES 5 and 6 ABOUT HERE}

For each of the three axes of vibration at the seat pan, the SEAT values were similar for single-axis random vibration and tri-axial random vibration (the median values differ by less than $3.2 \%$ ) and were not statistically significantly ( $p>0.05$, Wilcoxon). In the fore-and-aft direction to the seat backrest, the SEAT values were $10 \%$ greater with tri-axial random vibration than with single axis random vibration ( $p$ $<0.05$, Wilcoxon).

The SEAT values were greater with simulated train vibration than with tri-axial random vibration $(p \leq$ 0.003 , Wilcoxon). To the seat pan, the median measured SEAT values were $3 \%$ greater in the lateral direction, $10 \%$ greater in the fore-and-aft direction, and $21 \%$ greater in the vertical direction. To the backrest, the SEAT values for train vibration were $28 \%$ greater in the fore-and-aft direction.

The simulated train vibration also gave greater SEAT values than single-axis random excitation. To the seat pan, the median measured SEAT values were 12\% greater in the fore-and-aft direction, $2 \%$ greater in the lateral direction, and $8 \%$ greater in the vertical direction. To the seat backrest, the SEAT values 
Published as: Gong, W. and Griffin, M.J. (2018) Measuring, evaluating and assessing the transmission of vibration through the seats of railway vehicles. Proceedings of the Institution of Mechanical Engineers, Part F: Journal of Rail and Rapid Transit. 232, 2, p. 384-395.

for train vibration were $43 \%$ greater in the fore-and-aft direction, $2 \%$ less in the lateral direction, and $131 \%$ greater in the vertical direction.

The SEAT values measured to the seat pan with tri-axial random vibration did not differ from the SEAT values predicted using the transmissibility measured with single-axis random excitation: the median measured SEAT values for vertical vibration were about $1 \%$ less than predicted ( $p=0.944$, Wilcoxon). However, for fore-and-aft vibration at the seat backrest the SEAT values measured with tri-axial random vibration were $12 \%$ greater than predicted using the transmissibility measured with single-axis random excitation ( $p<0.01$, Wilcoxon).

\section{Subject variability}

The inter-subject variability in SEAT values was quantified by the ratio of the inter-quartile range in SEAT values to the median SEAT value in each axis. For vertical vibration on the seat surface, the ratio was 0.10 with tri-axial random vibration and 0.15 with simulated train vibration, indicating greater intersubject variability in SEAT values with the simulated train vibration.

There were no statistically significant correlations between subject mass (or body mass index) and SEAT values to the seat pan when using single-axis random vibration (Table 7).

\section{TABLE 7 ABOUT HERE}

The SEAT values for vertical vibration obtained with tri-axial excitation were correlated with those obtained with single-axis vertical excitation to both the seat pan and the backrest. So a subject giving a high SEAT value with single-axis vertical excitation also tended to give a high SEAT value in the z-axis when exposed to tri-axial excitation. The SEAT values for lateral seat pan and fore-and-aft backrest vibration were also correlated between tri-axial random excitation and single-axis random excitation (Table 7).

Apart from vertical vibration to the seat pan and the backrest, the SEAT values measured with simulated train vibration were not correlated with SEAT values measured with tri-axial random excitation.

The SEAT values predicted from the transmissibilities with single-axis random vibration were correlated with those measured with tri-axial random vibration, except in the fore-and-aft direction to the seat pan and the vertical direction at the backrest. The absence of a significant correlation in the $x$-axis at the seat pan may be explained by the small inter-subject variability in both the measured SEAT values (1.05 to 1.08$)$ and the predicted SEAT values (1.04 to 1.06).

The SEAT values predicted for the train vibration from the transmissibilities with single-axis random vibration were not correlated with those measured with the simulated train vibration, except for vertical vibration at the seat pan (Table 7). The absence of a significant correlation in the $x$-axis on the seat pan is associated with wide inter-subject variability in the measured SEAT values (1.08 to 1.36) but much less variability in the predicted SEAT values (1.01 to 1.06 ).

\section{Discussion}

\section{Transmissibilities}


Published as: Gong, W. and Griffin, M.J. (2018) Measuring, evaluating and assessing the transmission of vibration through the seats of railway vehicles. Proceedings of the Institution of Mechanical Engineers, Part F: Journal of Rail and Rapid Transit. 232, 2, p. 384-395.

The transmissibilities of the train seats measured in the laboratory with 12 subjects show some differences between tri-axial random excitation (using spectra from ISO 10326-2:2001) and tri-axial simulation of recorded train vibration. The principal differences are consistent with nonlinearities resulting in lower resonance frequencies with the greater magnitudes of the random vibration: the unweighted magnitude of $z$-axis vibration was $1.45 \mathrm{~ms}^{-2}$ r.m.s. for random excitation but only $0.15 \mathrm{~ms}^{-2}$ r.m.s. for simulated train vibration. The resonance frequency in the apparent mass of the body reduces with increasing magnitude of vibration ${ }^{10,16}$ and this nonlinearity in the response of the body can be the principal cause of reductions in the resonance frequency of a seat with greater magnitudes of vibration. ${ }^{3}$

Small differences in transmissibilities between single-axis random vibration and tri-axial random vibration are also consistent with the expected nonlinearity in the human body giving lower resonance frequencies with increased vibration with tri-axial excitation.

The coherencies measured with the single-axis random vibration tended to be greater than those measured with the tri-axial excitation, and can be explained by cross-axis effects as found in biodynamic studies. ${ }^{19,20}$ The coherencies measured with the tri-axial random vibration tended to be greater than those measured with the simulated train vibration. This is partly because the train vibration contained little energy at some frequencies in some axes. The tri-axial random vibration had excitations in the $x$-, $y$ - and z-axes that were not coherent with each other. The motions of the simulated train vibration were partially coherent in all three axes, which would artificially increase the coherence between the input and output signals used to calculate transmissibilities due to cross-axis effects.

If it is only desired to know the approximate transmissibility of a seat, this can be found using random vibration: the principal resonances are similar when using train vibration but the coherency is lower. There are no large differences between single-axis and tri-axial random vibration, so either may be considered acceptable when measuring the transmissibilities. The use of tri-axial random vibration has the advantage of reducing the duration of testing.

\section{SEAT values}

The difference in the SEAT values for vertical vibration to the seat pan with single-axis vertical excitation and tri-axial excitation (3.2\% difference in median values) may be considered negligible compared to the differences in SEAT values associated with inter-subject variability (up to $25 \%$ for the transmission of vertical vibration to the seat pan). The differences in the median SEAT values to the seat pan in both the lateral and the fore-and-aft directions between single-axis vertical excitation and tri-axial vertical random excitation are also small (less than $1 \%$ difference in median SEAT values) and negligible when compared to inter-subject variability. These small differences may be explained by non-linearity in the transmissibility, as explained above.

The SEAT values measured with the simulated train vibration differed from the SEAT values predicted from the transmissibilities measured with single axis random vibration, due to the large differences in the magnitudes of the train vibration and the random vibration and the nonlinearity in seat transmissibility. The differences could be reduced by predicting the SEAT values from transmissibilities measured using random vibration with a lower magnitude. Low magnitudes of train vibration in the $x$ - 
Published as: Gong, W. and Griffin, M.J. (2018) Measuring, evaluating and assessing the transmission of vibration through the seats of railway vehicles. Proceedings of the Institution of Mechanical Engineers, Part F: Journal of Rail and Rapid Transit. 232, 2, p. 384-395.

axis $\left(0.02 \mathrm{~ms}^{-2}\right.$ r.m.s.) make measurements with this direction of excitation susceptible to noise, giving low coherence and suggests the SEAT values predicted using random vibration may be more reliable than the SEAT values measured with train vibration.

With the simulated train vibration, the median SEAT values were $21 \%$ greater for vertical direction to the seat pan and $28 \%$ greater for fore-and-aft vibration to the backrest than with tri-axial random vibration. The dependence of the SEAT value on the input spectrum is not surprising, but has important implications for the use of ISO 10326-2:2001 to optimize passenger train seating. The SEAT value is a measure of how well a seat controls the vibration associated with a specific spectrum of vibration. Since trains do not have spectra similar to the random vibration required for the test in ISO 10326-2:2001, a SEAT value generated by the standard test cannot provide the best possible indicator of how a seat will control the vibration in a train. Alternatives are either to use vibration recorded in a train (or a standardised spectrum representing train vibration) when measuring SEAT values, or predict the SEAT values from train vibration spectra and seat transmissibility measured using random vibration excitation.

\section{Inter-subject variability}

The absence of significant correlations between subject mass and SEAT values suggests the selection of subjects based on their weight is not very useful, at least for the seat tested and the range of subject masses in this study (56 to $110 \mathrm{~kg}$ ). Toward and Griffin found that the strongest predictor of both the frequency of the principal resonance in seat transmissibility and the seat transmissibility at resonance was subject age, with other factors having only marginal effects. ${ }^{2}$ The tests specified in ISO 103262:2001 require two persons having masses of $55 \mathrm{~kg}(0$ to $-5 \%)$ and $90 \mathrm{~kg}(0$ to $+5 \%)$. These masses can be difficult to achieve, so relaxation of the required range of subject weights could be helpful and the introduction of an age specification appropriate.

The study has shown the expected large inter-subject variability in seat transmissibilities and SEAT values. In general, the use of only two subjects, as in ISO 10326-2:2001, is optimistic if it is desired to obtain a reliable indication of seat performance. However, the principal characteristics in the transmissibility of a seat (e.g., resonance frequencies) are similar with most subjects, so if transmissibilities are used solely to identify the principal seat resonances, they might be determined and presented for only one or two subjects. This would simplify the measurements and the reporting of the findings.

Inter-subject variability is likely to be important if the SEAT value is obtained in a suitable way (e.g., with suitable vibration spectra) and limiting values are specified for acceptable SEAT values. Assuming a normal distribution, the minimum sample, $N$, required for a desired margin of error, $M O E$, in a set of measures (e.g., in the resonance frequency or SEAT value) may be estimated as: ${ }^{21}$

$$
N \geq\left(\frac{z^{*} \sigma}{M O E}\right)^{2}
$$

where $z$ depends on the desired confidence level ( $z=1.96$ for a $95 \%$ confidence interval). If the population standard deviation, $\sigma$, is the same as the margin of error $(M O E)$, the calculated minimum 
Published as: Gong, W. and Griffin, M.J. (2018) Measuring, evaluating and assessing the transmission of vibration through the seats of railway vehicles. Proceedings of the Institution of Mechanical Engineers, Part F: Journal of Rail and Rapid Transit. 232, 2, p. 384-395.

sample size, $N$, is 3.84. So four subjects are sufficient if it is desired to obtain a mean SEAT value within $\pm \sigma$ (one standard deviation of the true SEAT value) and with a confidence interval of $95 \%$. Similarly, sixteen subjects are needed to obtain a mean SEAT value within $\pm 0.5 \sigma$.

\section{Modelling of seat dynamic response}

The principles for assessing the dynamic suitability of a seat as described in this paper could be used with values predicted by computer models when they become sufficient for the purpose. Because the transmissibility of a seat depends on the dynamic response of the human body as well as the dynamic characteristics of the seat, both are required in a suitable model. Generic models of the dynamic responses of the interaction between a body and a seat at both the seat pan and the backrest in three axes are not yet available. The dynamic responses seats differ between seats and so the characteristics of each seat (at the seat pan and the backrest) must be modelled in all three axes before it can be considered appropriate - this is complex and time-consuming. It is currently simpler to make measurements similar to those required by ISO 10326-2 and, even if the multi-axis responses of a seatpassenger combination are modelled, measurements will still be required to confirm the model predictions.

\section{Improvements to the standard}

To improve the evaluation of the transmission of vibration through the seats of railway vehicles, it is recommended that:

Seat transmissibilities are measured using the same spectra defined in ISO 10326-2:2001 but that it is permitted to use tri-axial vibration with three incoherent inputs. The results will be comparable to those obtained with the current single-axis tests, but can be obtained more quickly using tri-axial excitation.

The magnitude of the random vibration excitation is reduced to a level more similar to train vibration, to reduce errors caused by nonlinearity in the dynamic response of the seat-body system. The transmissibilities could be determined at two magnitudes of random vibration to include consideration of non-linearity.

SEAT values are determined for vibration appropriate to the train in which the seat will be used. There are several alternative methods of obtaining a suitable SEAT value:

By reproducing recordings of train vibration in the laboratory.

By reproducing standardised spectra representative of different classes of trains in the laboratory.

By calculating SEAT values from measures of seat transmissibility (obtained as in (i) and (ii) above) and either recordings of train vibration or representative spectra from different classes of trains.

Methods should be evolved to implement and compare all the alternatives in (iii) above, and compare the findings with additional measures of vibration recorded in a wide variety of trains and the corresponding SEAT values measured in the trains. 
Published as: Gong, W. and Griffin, M.J. (2018) Measuring, evaluating and assessing the transmission of vibration through the seats of railway vehicles. Proceedings of the Institution of Mechanical Engineers, Part F: Journal of Rail and Rapid Transit. 232, 2, p. 384-395.

The test in ISO 10326-2:2001 should be extended to include more than two subjects when measuring SEAT values but can be limited to one or two subjects when determining seat transmissibilities that are not used to calculate a SEAT value. The SEAT values should be presented in terms of the median and inter-quartile range of SEAT values obtained with at least four subjects having a range of characteristics considered representative of the travelling public.

\section{Conclusions}

There are small differences in transmissibilities and SEAT values obtained using single-axis and triaxial vibration excitation, so either single-axis or tri-axial excitation could provide useful information when evaluating seat transmissibility using methods similar to those in ISO 10326-2 (2001).

Single-axis random vibration or tri-axial random vibration with the magnitude specified in ISO 103262:2001 allows the identification of the principal seat resonances, but the resonances differ from those likely with the lower magnitudes of train vibration. A test to identify resonances could be simplified by using tri-axial random vibration and a single subject. The use of two magnitudes of tri-axial random vibration would allow consideration of non-linearity.

The calculation of a SEAT value for a railway passenger seat must take into account the vibration spectra in the train in which the seat will be used, and should be based on measurements with more than the two subjects currently specified in ISO 10326-2:2001.

\section{Funding}

The authors would like to thank Société Nationale des Chemins de fer Français (SNCF), Paris, France, for their financial support.

\section{Acknowledgements}

The assistance of Cedric Gallais is gratefully acknowledged.

\section{References}

1. Griffin MJ. Discomfort from feeling vehicle vibration. Vehicle System Dynamics 2007; 45, (7-8), 679698. (doi:10.1080/00423110701422426).

2. Toward MGR and Griffin MJ. The transmission of vertical vibration through seats: Influence of the characteristics of the human body. Journal of Sound and Vibration 2011; 330:, 6526-6543.

3. Tufano $S$ and Griffin MJ. Nonlinearity in the vertical transmissibility of seating: The role of the human body apparent mass and seat dynamic stiffness. Vehicle System Dynamics, 2013; 51, (1), 122-138. (doi:10.1080/00423114.2012.715652).

4. Corbridge C, Griffin MJ and Harborough P. Seat dynamics and passenger comfort. Proceedings of the Institution of Mechanical Engineers 1989; 203, 57-64.

5. Griffin MJ. The evaluation of vehicle vibration and seats. Applied Ergonomics 1978; 9(1) 15-21. (doi:10.1016/0003-6870(78)90214-4)

6. Basri B and Griffin MJ. The application of SEAT values for predicting how compliant seats with backrests influence vibration discomfort. Applied Ergonomics 2014; 45, 1461-1474. 
Published as: Gong, W. and Griffin, M.J. (2018) Measuring, evaluating and assessing the transmission of vibration through the seats of railway vehicles. Proceedings of the Institution of Mechanical Engineers, Part F: Journal of Rail and Rapid Transit. 232, 2, p. 384-395.

7. British Standards Institution. Guide to Measurement and Evaluation of Human Exposure to WholeBody Mechanical Vibration and Repeated Shock. BS 6841:1987.

8. International Organization for Standardization. Mechanical vibration and shock - evaluation of human exposure to whole-body vibration - Part 1: General requirements, International Standard, ISO 2631-1.

9. Ebe K and Griffin MJ. Factors affecting static seat cushion comfort. Ergonomics 2001; 44, (10), $901-$ 21. (doi:10.1080/00140130110064685).

10. Fairley TE and Griffin MJ. The apparent mass of the seated human body: vertical vibration. J. Biomechanics 1989; 22:, 81-94.

11. Matsumoto $Y$ and Griffin MJ Non-linear characteristics in the dynamic responses of seated subjects exposed to vertical whole-body vibration. Journal of Biomedical Engineering 2002; 124, 527-532.

12. International Organization for Standardization. Mechanical vibration - Laboratory method for evaluating vehicle seat vibration - Part 2 Application to railway vehicles. ISO 10326-2:2001.

13. Gong W and Griffin MJ. Seat transmissibility measured with single-axis and tri-axial vibration excitation, $47^{\text {th }}$ United Kingdom Conference on Human Responses to Vibration, ISVR, University of Southampton, Southampton, England, 17 - 19 September 2012.

14. Rimell AN and Mansfield NJ. Multi-axis transmissibility measurements for different vehicle seats, 40th United Kingdom Conference on Human Response to Vibration, Liverpool, England, September 2005.

15. Gong W and Griffin MJ. Comparison of the transmissibility and SEAT values of a passenger train seat using tri-axial random vibration and simulated train vibration, 48th United Kingdom Conference on Human Responses to Vibration, held at Andreas Stihl Limited, Surrey, UK, 16 - 18 September 2013.

16. Zhou $Z$ and Griffin MJ. Response of the seated human body to whole-body vertical vibration: biodynamic responses to sinusoidal and random vibration. Ergonomics, 2014; 57, (5), 714-732. (doi:10.1080/00140139.2014.898799).

17. International Organization for Standardization. Mechanical vibration - Laboratory method for evaluating vehicle seat vibration - Part 1 Basic requirements. ISO 10326-1:1992.

18. Qiu Y and Griffin MJ. Transmission of vibration to the backrest of a car seat evaluated with multiinput models. Journal of Sound and Vibration 2004; 274, $297-321$.

19. Qiu Y and Griffin MJ Biodynamic responses of the seated human body to single-axis and dual-axis vibration. Industrial Health, 2010;, 48(5);, 615-627.

20. Nawayseh N and Griffin MJ Tri-axial forces at the seat and backrest during whole-body vertical vibration. Journal of Sound and Vibration 2004; 277, 309-326.

21. Rumsey DJ Statistics for Dummies, John Wiley \& Son, Second Edition, 2011; p166. 


\section{Figure Captions}

Figure 1 The train double seat with transducers.

Figure 2 Power spectral densities of the random vibration excitation (- - - -) and simulated train vibration (-). Frequency resolution $0.25 \mathrm{~Hz}$.

Figure 3 Seat transmissibilities (moduli and phases) and coherencies measured with 12 individual subjects using single-axis random excitation. The graphs are labelled in the form seat- $x$, seat- $y$, seat$z$, and backrest- $x$, backrest- $y$, backrest- $z$ where ' $x$ ' indicates that both the excitation and the response are in the fore-and-aft direction, ' $y$ ' indicates that both the excitation and the response are in the lateral direction, and ' $z$ ' indicates that both the excitation and the response are in the vertical direction.

Figure 4 Median seat transmissibilities (moduli and phases) and coherencies measured with 12 subjects using single-axis random excitation, tri-axial random excitation, and tri-axial simulated train vibration. The graphs are labelled in the form seat- $x$, seat- $y$, seat- $z$, and backrest- $x$, backrest- $y$, backrest- $z$ where ' $x$ ' indicates that both the excitation and the response are in the fore-and-aft direction, ' $y$ ' indicates that both the excitation and the response are in the lateral direction, and ' $z$ ' indicates that both the excitation and the response are in the vertical direction. 
Published as: Gong, W. and Griffin, M.J. (2018) Measuring, evaluating and assessing the transmission of vibration through the seats of railway vehicles. Proceedings of the Institution of Mechanical Engineers, Part F: Journal of Rail and Rapid Transit. 232, 2, p. 384-395.

Table 1 Characteristics of test subjects.

\begin{tabular}{ccccc}
\hline Subject & Gender & Stature $(\mathrm{m})$ & Mass $(\mathrm{kg})$ & Age (years) \\
& & & & \\
\hline 1 & Male & 1.75 & 79 & 44 \\
2 & Male & 1.78 & 73 & 24 \\
3 & Male & 1.86 & 79 & 57 \\
4 & Male & 1.82 & 86 & 25 \\
5 & Male & 1.97 & 110 & 25 \\
6 & Male & 1.75 & 72 & 32 \\
7 & Male & 1.86 & 76 & 21 \\
8 & Male & 1.78 & 62 & 28 \\
9 & Male & 1.64 & 62 & 34 \\
10 & Male & 1.65 & 56 & 28 \\
11 & Male & 1.65 & 67 & 28 \\
12 & Male & 1.69 & 61 & 26 \\
average & - & 1.76 & 73.6 & 36.1 \\
\hline
\end{tabular}


Table 2 Magnitudes of the acceleration excitation on the vibrator platform in each axis with random vibration excitation according to ISO 10326-1:2001 and the simulation of recorded train vibration. (Frequency weighting $W_{\mathrm{k}}$ has been applied to vertical vibration as required by ISO 2631-1:1997, although $W_{b}$ is recommended in BS 6841:1987 and usually preferred for evaluating railway vibration).

\begin{tabular}{lccccc}
\hline $\begin{array}{c}\text { Excitation } \\
\text { type }\end{array}$ & Direction & $\begin{array}{c}\text { Frequency } \\
\text { weighting }\end{array}$ & $\begin{array}{c}\text { Multiplying } \\
\text { factor }\end{array}$ & $\begin{array}{c}\text { Unweighted } \\
\text { accelerations } \\
\left(\mathrm{ms}^{-2} \text { r.m.s. }\right)\end{array}$ & $\begin{array}{c}\text { Weighted } \\
\text { accelerations } \\
\left(\mathrm{ms}^{-2} \text { r.m.s. }\right)\end{array}$ \\
\hline $\begin{array}{l}\text { Single-axis } \\
\text { random }\end{array}$ & $x$ & $W_{\mathrm{d}}$ & 1.0 & 1.34 & 0.38 \\
vibration & $\mathrm{z}$ & $W_{\mathrm{d}}$ & 1.0 & 1.35 & 0.38 \\
& & $W_{\mathrm{k}}$ & 1.0 & 1.47 & 0.97 \\
Tri-axial & $x$ & $W_{\mathrm{d}}$ & 1.0 & 1.36 & 0.39 \\
random & $y$ & $W_{\mathrm{d}}$ & 1.0 & 1.37 & 0.39 \\
vibration & $z$ & $W_{\mathrm{k}}$ & 1.0 & 1.45 & 0.98 \\
& & & & & \\
Tri-axial & $x$ & $W_{\mathrm{d}}$ & 1.0 & 0.04 & 0.02 \\
train & $y$ & $W_{\mathrm{d}}$ & 1.0 & 0.13 & 0.09 \\
vibration & $z$ & $W_{\mathrm{k}}$ & 1.0 & 0.15 & 0.10 \\
\hline
\end{tabular}


Published as: Gong, W. and Griffin, M.J. (2018) Measuring, evaluating and assessing the transmission of vibration through the seats of railway vehicles. Proceedings of the Institution of Mechanical Engineers, Part F: Journal of Rail and Rapid Transit. 232, 2, p. 384-395.

Table 3 Frequency weightings for vibration discomfort as defined in ISO 2631-1:1997.

\begin{tabular}{lcccccc}
\hline Location & \multicolumn{3}{c}{ Seat surface } & & Backrest \\
\hline Axis & x-axis & $y$-axis & z-axis & $x$-axis & $y$-axis & z-axis \\
\hline $\begin{array}{l}\text { Frequency } \\
\text { weighting }\end{array}$ & $W_{\mathrm{d}}$ & $W_{\mathrm{d}}$ & $W_{\mathrm{k}}$ & $W_{\mathrm{c}}$ & $W_{\mathrm{d}}$ & $W_{\mathrm{d}}$ \\
\hline $\begin{array}{l}\text { Multiplying } \\
\text { factor }\end{array}$ & 1.0 & 1.0 & 1.0 & 0.8 & 0.5 & 0.4 \\
\hline
\end{tabular}


Published as: Gong, W. and Griffin, M.J. (2018) Measuring, evaluating and assessing the transmission of vibration through the seats of railway vehicles. Proceedings of the Institution of Mechanical Engineers, Part F: Journal of Rail and Rapid Transit. 232,2 , p. $384-395$.

Table 4 Resonance frequencies and transmissibilities at resonance (medians for 12 subjects).

\begin{tabular}{cccccccc}
\hline & & \multicolumn{3}{c}{ Seat surface } & \multicolumn{3}{c}{ Seat backrest } \\
\cline { 2 - 7 } & & $x$-axis & $y$-axis & z-axis & $x$-axis & $y$-axis & z-axis \\
\hline & $\begin{array}{c}\text { Single-axis } \\
\text { random }\end{array}$ & 1.70 & 1.45 & 2.20 & 1.71 & 3.25 & 2.34 \\
$\begin{array}{c}\text { Transmissibility } \\
\text { at resonance }\end{array}$ & $\begin{array}{c}\text { Tri-axial } \\
\text { random }\end{array}$ & 1.69 & 1.51 & 2.05 & 1.76 & 3.23 & 2.23 \\
& $\begin{array}{c}\text { Simulated } \\
\text { train }\end{array}$ & 2.01 & 1.46 & 2.26 & 3.32 & 5.50 & 2.95 \\
\hline $\begin{array}{c}\text { Single-axis } \\
\text { random }\end{array}$ & 25.7 & 24.0 & 4.0 & 4.1 & 24.5 & 24.0 \\
Resonance & $\begin{array}{c}\text { Tri-axial } \\
\text { random }\end{array}$ & 25.8 & 23.5 & 3.8 & 4.2 & 23.8 & 24.0 \\
Frequency $(\mathrm{Hz})$ & $\begin{array}{c}\text { Simulated } \\
\text { train }\end{array}$ & 26.4 & 25.0 & 5.0 & 5.1 & 25.0 & 25.0 \\
\hline
\end{tabular}


Table 5 Measured and predicted SEAT values to the seat pan obtained with simulated train vibration, tri-axial random vibration, and single-axis random vibration (individual values from 12 subjects, median values, and inter-quartile ranges, IQR). Predictions based on single-axis transmissibilities.

\begin{tabular}{|c|c|c|c|c|c|c|c|c|c|c|c|c|c|c|c|}
\hline \multirow[t]{3}{*}{ Subject } & \multicolumn{6}{|c|}{ Simulated train vibration } & \multicolumn{6}{|c|}{ Tri-axial random vibration } & \multirow{2}{*}{\multicolumn{3}{|c|}{$\begin{array}{c}\text { Single-axis } \\
\text { random } \\
\text { vibration } \\
\text { measured }\end{array}$}} \\
\hline & \multicolumn{3}{|c|}{ measured } & \multicolumn{3}{|c|}{ predicted } & \multicolumn{3}{|c|}{ measured } & \multicolumn{3}{|c|}{ predicted } & & & \\
\hline & $x$ & $y$ & $z$ & $x$ & $y$ & $z$ & $x$ & $y$ & $z$ & $x$ & $y$ & $z$ & $x$ & $y$ & $z$ \\
\hline 1 & 1.11 & 1.06 & 1.13 & 1.06 & 1.04 & 1.09 & 1.05 & 1.03 & 0.83 & 1.06 & 1.01 & 1.00 & 1.06 & 1.01 & 1.05 \\
\hline 2 & 1.15 & 1.09 & 1.03 & 1.03 & 1.06 & 0.95 & 1.05 & 1.02 & 0.86 & 1.04 & 1.02 & 0.83 & 1.05 & 1.02 & 0.79 \\
\hline 3 & 1.16 & 1.03 & 1.06 & 1.06 & 1.04 & 1.05 & 1.08 & 1.02 & 0.93 & 1.06 & 1.01 & 0.92 & 1.06 & 1.01 & 0.95 \\
\hline 4 & 1.27 & 1.06 & 1.20 & 1.04 & 1.05 & 1.13 & 1.07 & 1.03 & 1.05 & 1.05 & 1.03 & 1.05 & 1.05 & 1.03 & 1.05 \\
\hline 5 & 1.22 & 1.08 & 1.10 & 1.03 & 1.05 & 1.01 & 1.05 & 1.01 & 0.90 & 1.04 & 1.01 & 0.93 & 1.05 & 1.01 & 0.94 \\
\hline 6 & 1.15 & 1.14 & 1.06 & 1.04 & 1.04 & 0.99 & 1.06 & 1.03 & 0.92 & 1.05 & 1.03 & 0.90 & 1.05 & 1.03 & 0.92 \\
\hline 7 & 1.16 & 1.07 & 1.10 & 1.05 & 1.04 & 1.02 & 1.05 & 1.03 & 0.92 & 1.06 & 1.02 & 0.92 & 1.06 & 1.02 & 0.94 \\
\hline 8 & 1.25 & 1.06 & 1.03 & 1.06 & 1.00 & 0.99 & 1.08 & 1.00 & 0.90 & 1.06 & 1.00 & 0.89 & 1.06 & 1.00 & 0.92 \\
\hline 9 & 1.36 & 1.03 & 1.31 & 1.01 & 1.0 & 1.10 & 1.06 & 1.04 & 1.08 & 1.04 & 1 & 1.05 & 1.05 & 1.02 & 1.06 \\
\hline 10 & 1.08 & 1.11 & 0.99 & 1.05 & 1.10 & 0.90 & 1.05 & 1.04 & 0.81 & 1.05 & 1.05 & 0.81 & 1.05 & 1.05 & 0.83 \\
\hline 11 & 1.22 & 1.05 & 1.19 & 1.03 & 1.03 & 1.08 & 1.05 & 1.03 & 0.98 & 1.04 & 1.03 & 1.00 & 1.05 & 1.03 & 1.02 \\
\hline 12 & 1.15 & 1.06 & 1.10 & 1.04 & 1.07 & 1.02 & 1.07 & 1.03 & 0.87 & 1.05 & 1.02 & 0.87 & 1.05 & 1.02 & 0.90 \\
\hline median & 1.16 & 1.06 & 1.10 & 1.04 & 1.04 & 1.02 & 1.05 & 1.03 & 0.91 & 1.05 & 1.02 & 0.92 & 1.05 & 1.02 & 0.94 \\
\hline IQR & 0.10 & 0.04 & 0.16 & 0.03 & 0.02 & 0.10 & 0.02 & 0.01 & 0.09 & 0.02 & 0.02 & 0.12 & 0.01 & 0.02 & 0.13 \\
\hline
\end{tabular}


Table 6 Measured and predicted SEAT values to the seat backrest obtained with simulated train vibration, tri-axial random vibration, and single-axis random vibration (individual values from 12 subjects, median values, and inter-quartile ranges, IQR). Predictions based on single-axis transmissibilities.

\begin{tabular}{cccccccccccccccc} 
Subject & \multicolumn{1}{c}{ measured } & \multicolumn{1}{c}{ predicted } & \multicolumn{1}{c}{ measured } & \multicolumn{4}{c}{ predicted } & \multicolumn{4}{c}{ measured } \\
\cline { 2 - 6 } & \multicolumn{1}{c}{$y$} & $y$ & $z$ & $x$ & $y$ & $z$ & $x$ & $y$ & $z$ & $x$ & $y$ & $z$ & $x$ & $y$ & $z$ \\
\hline 1 & 2.22 & 0.51 & 0.38 & 1.29 & 0.51 & 0.38 & 2.08 & 0.54 & 0.17 & 1.70 & 0.52 & 0.17 & 1.72 & 0.53 & 0.16 \\
\hline 2 & 2.53 & 0.52 & 0.38 & 1.40 & 0.51 & 0.37 & 1.85 & 0.55 & 0.17 & 2.04 & 0.52 & 0.17 & 2.10 & 0.51 & 0.16 \\
\hline 3 & 2.65 & 0.52 & 0.37 & 1.23 & 0.51 & 0.37 & 3.07 & 0.56 & 0.17 & 1.86 & 0.53 & 0.16 & 1.92 & 0.53 & 0.16 \\
\hline 4 & 2.25 & 0.52 & 0.39 & 1.34 & 0.50 & 0.40 & 1.97 & 0.53 & 0.18 & 1.87 & 0.52 & 0.17 & 1.92 & 0.51 & 0.17 \\
\hline 5 & 2.45 & 0.51 & 0.38 & 1.22 & 0.50 & 0.38 & 1.75 & 0.53 & 0.18 & 1.53 & 0.51 & 0.17 & 1.55 & 0.51 & 0.17 \\
\hline 6 & 2.81 & 0.52 & 0.37 & 1.22 & 0.50 & 0.38 & 1.77 & 0.54 & 0.17 & 1.59 & 0.52 & 0.16 & 1.66 & 0.53 & 0.16 \\
\hline 7 & 2.60 & 0.52 & 0.37 & 1.27 & 0.50 & 0.37 & 1.96 & 0.55 & 0.17 & 1.72 & 0.53 & 0.16 & 1.74 & 0.53 & 0.17 \\
\hline 8 & 2.22 & 0.52 & 0.37 & 1.20 & 0.51 & 0.38 & 1.95 & 0.54 & 0.17 & 1.73 & 0.53 & 0.16 & 1.76 & 0.53 & 0.16 \\
\hline 9 & 2.47 & 0.52 & 0.36 & 1.16 & 0.50 & 0.37 & 1.97 & 0.56 & 0.16 & 1.76 & 0.52 & 0.16 & 1.79 & 0.53 & 0.16 \\
\hline 10 & 2.56 & 0.51 & 0.37 & 1.17 & 0.52 & 0.38 & 2.01 & 0.55 & 0.18 & 1.82 & 0.53 & 0.16 & 1.92 & 0.53 & 0.17 \\
\hline 11 & 2.38 & 0.51 & 0.37 & 1.18 & 0.50 & 0.37 & 1.69 & 0.54 & 0.17 & 1.57 & 0.52 & 0.16 & 1.59 & 0.53 & 0.16 \\
\hline 12 & 2.51 & 0.53 & 0.37 & 1.22 & 0.50 & 0.38 & 1.80 & 0.56 & 0.16 & 1.70 & 0.53 & 0.16 & 1.72 & 0.51 & 0.16 \\
\hline median & $\mathbf{2 . 5 1}$ & $\mathbf{0 . 5 2}$ & $\mathbf{0 . 3 7}$ & $\mathbf{1 . 2 2}$ & $\mathbf{0 . 5 0}$ & $\mathbf{0 . 3 8}$ & $\mathbf{1 . 9 5}$ & $\mathbf{0 . 5 4}$ & $\mathbf{0 . 1 7}$ & $\mathbf{1 . 7 3}$ & $\mathbf{0 . 5 2}$ & $\mathbf{0 . 1 6}$ & $\mathbf{1 . 7 5}$ & $\mathbf{0 . 5 3}$ & $\mathbf{0 . 1 6}$ \\
\hline IQR & $\mathbf{0 . 1 9}$ & $\mathbf{0 . 0 1}$ & $\mathbf{0 . 0 1}$ & $\mathbf{0 . 0 9}$ & $\mathbf{0 . 0 1}$ & $\mathbf{0 . 0 1}$ & $\mathbf{0 . 1 8}$ & $\mathbf{0 . 0 2}$ & $\mathbf{0 . 0 1}$ & $\mathbf{0 . 2 0}$ & $\mathbf{0 . 0 1}$ & $\mathbf{0 . 0 1}$ & $\mathbf{0 . 2 3}$ & $\mathbf{0 . 0 2}$ & $\mathbf{0 . 0 1}$ \\
\hline
\end{tabular}


Table 7 Correlation between individual characteristics and SEAT values (Spearman rank correlation coefficients and $p=v a l u e s$ for 12 subjects).

\begin{tabular}{|c|c|c|c|c|c|}
\hline Variable 1 & Subject mass & $\begin{array}{c}\text { Measured SEAT } \\
\text { values with tri-axial } \\
\text { random vibration }\end{array}$ & $\begin{array}{l}\text { Measured SEAT } \\
\text { values with tri-axial } \\
\text { random vibration }\end{array}$ & $\begin{array}{l}\text { Measured SEAT } \\
\text { values with tri-axial } \\
\text { random vibration }\end{array}$ & $\begin{array}{c}\text { Measured SEAT } \\
\text { values with simulated } \\
\text { train vibration }\end{array}$ \\
\hline Variable 2 & $\begin{array}{l}\text { Measured SEAT } \\
\text { values with single- } \\
\text { axis random } \\
\text { excitation }\end{array}$ & $\begin{array}{c}\text { Measured SEAT values } \\
\text { with single-axis random } \\
\text { vibration }\end{array}$ & $\begin{array}{c}\text { Measured SEAT } \\
\text { values with } \\
\text { simulated train } \\
\text { vibration }\end{array}$ & $\begin{array}{l}\text { Predicted SEAT } \\
\text { values for tri-axial } \\
\text { random vibration }\end{array}$ & $\begin{array}{c}\text { Predicted SEAT } \\
\text { values for simulated } \\
\text { train vibration }\end{array}$ \\
\hline Seat_x & $r=0.231, p=0.470$ & $r=0.220, p=0.492$ & $r=0.395, p=0.204$ & $r=0.381, p=0.222$ & $r=-0.367$, \\
\hline Seat_y & $r=-0.328, p=0.298$ & $r=0.705, p=0.011$ & $r=-0.025, p=0.939$ & $r=0.813, p=0.001$ & $r=0.544, p=0.068$ \\
\hline Seat_z & $r=0.416, p=0.178$ & $r=0.674, p=0.016$ & $r=0.649, p=0.022$ & $r=0.714, p=0.009$ & $r=0.918, p=0.001$ \\
\hline Backrest_x & $r=-0.112, p=0.730$ & $r=0.640, p=0.025$ & $r=0.035, p=0.914$ & $r=0.625, p=0.030$ & $r=0.007, p=0.983$ \\
\hline Backrest_y & $r=-0.308, p=0.330$ & $r=0.212, p=0.508$ & $r=-0.489, p=0.107$ & $r=0.584, p=0.046$ & $r=-0.266, p=0.404$ \\
\hline Bacl & $r=0.308, p=0.330$ & $r=0.751, p=0.005$ & $r=0.612, p=0.034$ & $r=0.462, p=0.131$ & $r=0.481, p=0.113$ \\
\hline
\end{tabular}




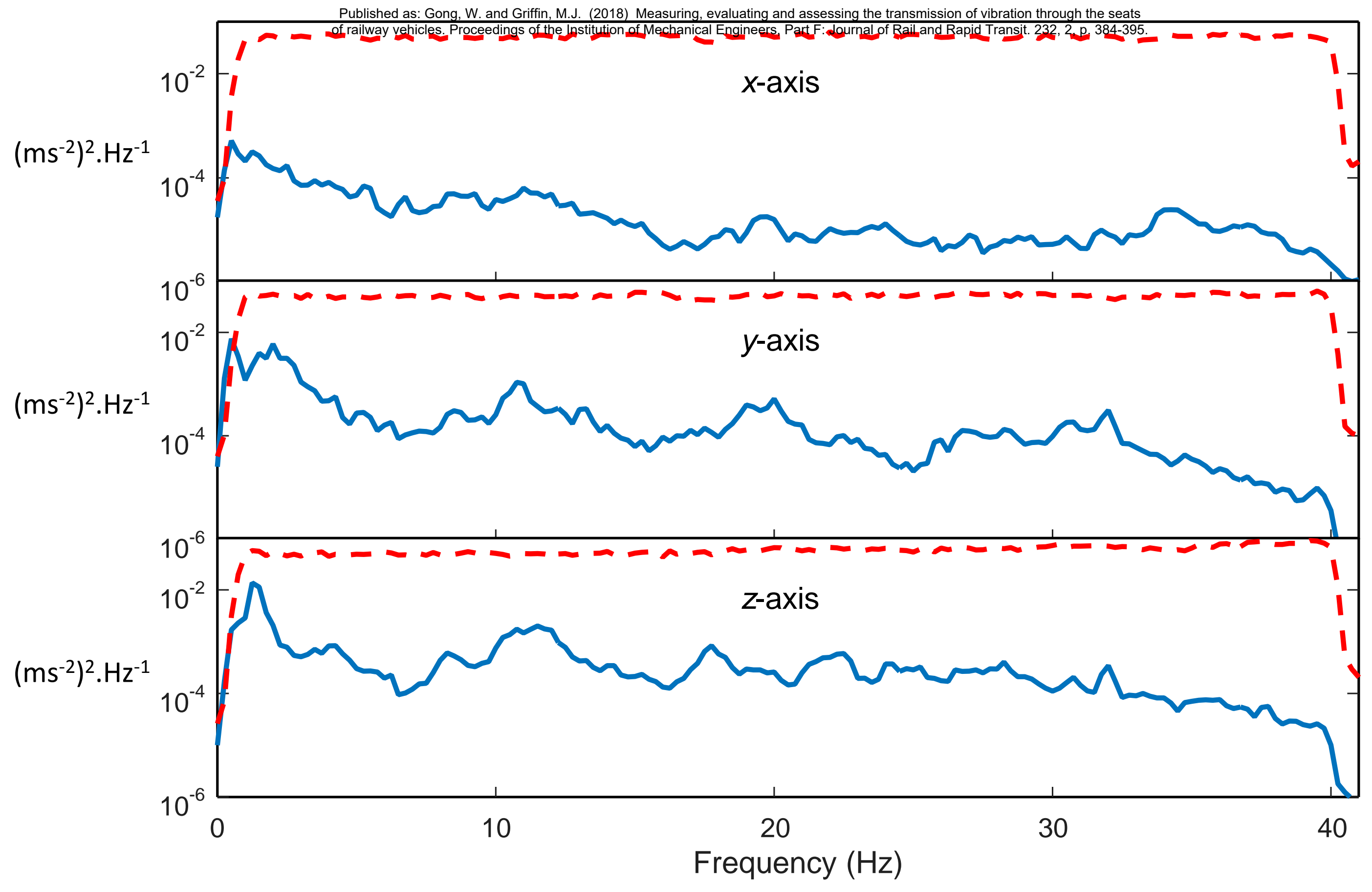


Published as: Gong, W. and Griffin, M.J. (2018) Measuring, evaluating and assessing the transmission of vibration through the seats of railway vehicles. Proceedings of the Institution of Mechanical Engineers, Part F: Journal of Rail and Rapid Transit. 232, 2, p. 384-395.

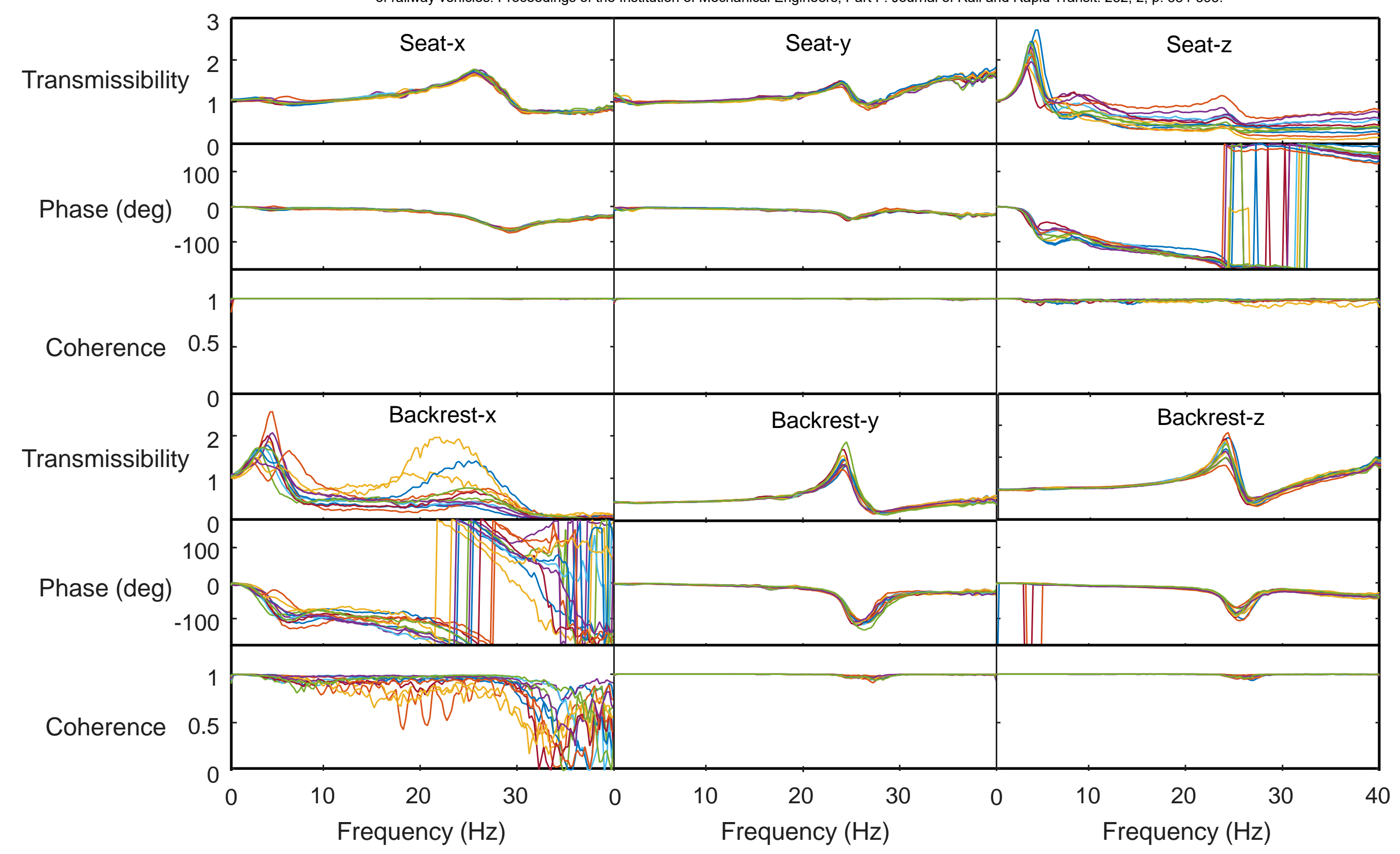




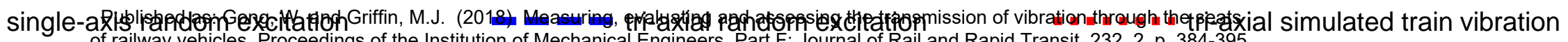

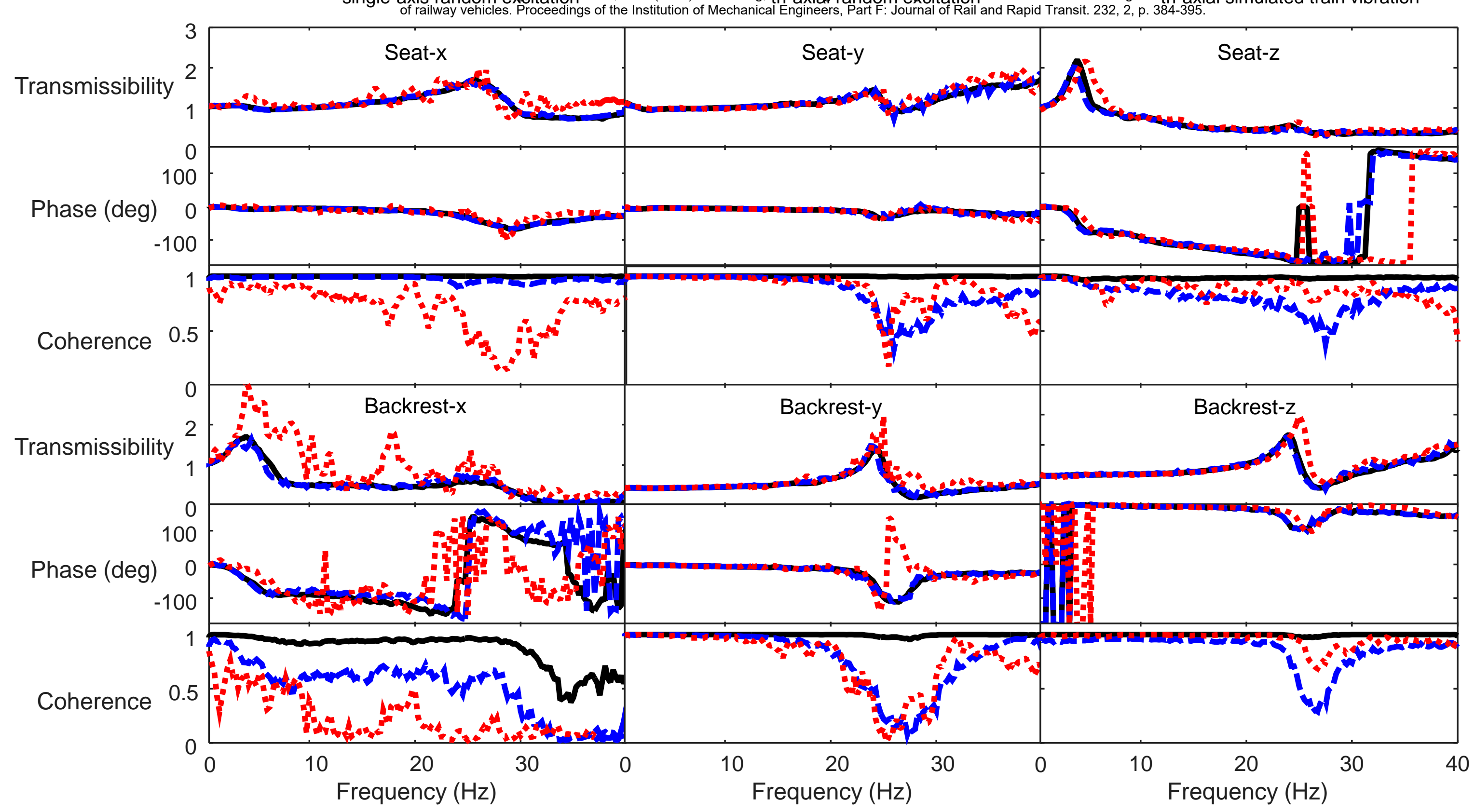

